\title{
The prevalence and nosocomial acquisition of Clostridium difficile in elderly hospitalized patients
}

\author{
B. Rudensky, S. Rosner, M. Sonnenblick ${ }^{1}$, Y. van Dijk ${ }^{1}$, E. Shapira ${ }^{2}$ and \\ M. Isaacsohn ${ }^{3}$
}

Departments of Clinical Microbiology, ${ }^{1}$ Geriatrics, ${ }^{2}$ Chronic Care and ${ }^{3}$ Infectious Diseases, Shaare Zedek Medical Center, Jerusalem, Israel

Summary: Rectal swabs obtained from 10 of 49 chronic-care geriatric patients were positive for Clostridium difficile, for a prevalence rate of $20.4 \%$. Simultaneous sampling of 29 patients in an acute geriatric ward revealed four colonized patients, for a prevalence rate of $13.7 \%$.

A prospective study of $C$. difficile colonization in 100 consecutive patients admitted to an acute geriatric ward was carried out. All patients were sampled upon admission and biweekly during hospitalization. Two patients $(2 \%)$ were positive on admission, and 12 of the 98 initially negative patients became colonized, representing a nosocomial acquisition rate of $12.2 \%$. A major determinant for $C$. difficile colonization in asymptomatic patients appears to be length of hospitalization. Previous antibiotic administration was not found to be a significant factor.

\section{Introduction}

Clostridium difficile has been implicated as causing diarrhoea and colitis, especially in hospitalized patients receiving antibiotic therapy. ${ }^{1}$ Outbreaks of $C$. difficile diarrhoea have been reported and have been associated with prevalence rates of $C$. difficile colonization in up to $47 \%$ of hospitalized patients. $^{2-4}$ As most studies of colonization prevalence were in epidemic settings and as two studies ${ }^{5,6}$ concluded that $C$. difficile is not endemic in elderly asymptomatic patients, we decided to carry out a prevalence study in an acute and in a chronic care geriatric ward under non-epidemic conditions. Environmental cultures were also performed to study possible sources of infection. In addition, we attempted to study prospectively the rate of nosocomial acquisition of $C$. difficile infection.

\section{Methods}

\section{Patients and environmental samples}

For the prevalence study, all 49 patients in the geriatric chronic-care ward and all 29 patients in

Correspondence: B. Rudensky, Ph.D., Department of Clinical Microbiology, Shaare Zedek Medical Center, Jerusalem, PO Box 3235, Israel.

Accepted: 23 July 1992 the acute care ward were cultured by rectal swab for presence of $C$. difficile. For the prospective study, 100 consecutive patients admitted to the acute care ward were cultured by rectal swab within 24 hours of admission. Biweekly cultures were taken until discharge or death. Table I describes the different patient populations. The study was approved by our Institutional Ethics Committee.

Environmental samples were taken at the time of our prevalence study. Sterile premoistened swabs were wiped across the hands and fingernails of medical, nursing and housekeeping staff and across environmental areas such as bedpans, toilets, bedpan washers, bedrails, walls and sinks in both the acute and chronic wards.

\section{Laboratory methods}

Rectal swabs and environmental specimens were transported in Amies medium without charcoal (Transwab, Medical Wire and Equipment Co., England) and were inoculated within 20 minutes on to selective difficile agar, containing cycloserine $(0.25 \mu \mathrm{g} / \mathrm{ml})$ and cefoxitin $(16 \mu \mathrm{g} / \mathrm{ml})$, and into enrichment broth consisting of supplemented peptone and cefoxitin $(39 \mu \mathrm{g} / \mathrm{ml})$, as previously described. ${ }^{7}$ Cultures were incubated anaerobically for 48 hours at $35^{\circ} \mathrm{C}$ in GasPak jar (BBL Microbiology Systems, Cockeysville, MD). Isolates having characteristic growth and microscopic morphology were identified by using the Rap ID-ANA system (Innovative Diagnostic Systems, Atlanta, GA) ${ }^{8}$ 


\section{Results}

Results are summarized in Table II. Ten of 49 patients in the chronic-care ward were colonized with $C$. difficile, for a prevalence rate of $20.4 \%$. No significant difference was found between colonized or non-colonized patients with regard to having received antibiotic therapy during the past 2 weeks ( $30 \%$ of colonized patients vs $28 \%$ of non-colonized patients). Four of 29 acute geriatric patients were colonized with $C$. difficile, for a prevalence rate of $13.7 \%$. Although prior in-hospital antibiotic therapy was more prevalent in colonized $v s$ non-colonized patients $(100 \%$ vs $76 \%)$, length of hospitalization appeared to be the significant contributor to prevalence of colonization (average of 21.6 days hospitalization for colonized patients $v s$ 11.7 days hospitalization for non-colonized patients).

Environmental cultures were positive for $C$. difficile in $16 \%$ of specimens from bedpans prior to washing, $12 \%$ of specimens from toilets, and $5 \%$ of specimens taken at different hours from the bedpan washers. None of the specimens taken from staff members, bedrails, walls or sinks were positive.

Two of the 100 patients prospectively studied were colonized upon admission and $12(12.2 \%)$ subsequently became nosocomially colonized. During their hospitalization $86 \%$ of colonized patients received antibiotics $v s 76 \%$ of non-colonized patients. Although five patients were already colonized by the second week, patients continued becoming colonized during the duration of their hospitalization, with some becoming colonized after 5 weeks. None of the colonized patients in the prevalence nor in the prospective study showed clinical signs attributable to $C$. difficile infection.

\section{Discussion}

The prevalence of $C$. difficile colonization in our study is similar to that reported by others. ${ }^{2-4,9}$ Unlike Campbell et al..$^{5}$ and Corrado et al. ${ }^{6}$ who concluded that $C$. difficile is not part of normal faecal flora of elderly patients, we cultured the organism from $12-20 \%$ of acute and chronic geriatric patients, although our study encompassed a period of no epidemic outbreaks of diarrhoeal disease. Our finding of similar prevalence of antibiotic therapy in the colonized and non-colonized groups was somewhat surprising, but Thomas et $a l .{ }^{10}$ also reported finding no significant association between infection and treatment with what are considered high-risk antibiotics.

Our findings of a $12.2 \%$ nosocomial acquisition rate is similar, but a bit lower than the $21 \%$ rate found by others. ${ }^{11,12}$

Table I Patient description

\begin{tabular}{lcccc}
\hline Patient group & Men & Women & $\begin{array}{c}\text { Median age } \\
\text { (years) }\end{array}$ & $\begin{array}{c}\text { Average length of } \\
\text { hospitalization }\end{array}$ \\
\hline $\begin{array}{l}\text { Chronic-care prevalence } \\
\quad \text { study }(n=49)\end{array}$ & 15 & 34 & $\begin{array}{c}75.3 \\
(68-106)\end{array}$ & $\begin{array}{c}2.5 \text { years } \\
(0.5-8.5)\end{array}$ \\
$\begin{array}{l}\text { Acute-care prevalence } \\
\quad \text { study }(n=29)\end{array}$ & 18 & 11 & $\begin{array}{c}80 \\
(56-101)\end{array}$ & $\begin{array}{c}12.9 \text { days } \\
(4-31)\end{array}$ \\
$\begin{array}{l}\text { Prospective study }(n=100) \\
\text { ros }\end{array}$ & 41 & 59 & $\begin{array}{c}79.3 \\
(59-102)\end{array}$ & $\begin{array}{c}16.5 \text { days } \\
(3-70)\end{array}$ \\
\hline
\end{tabular}

Table II Clostridium difficile colonization and previous antibiotic therapy

\begin{tabular}{lcccc}
\hline Patient source & $\begin{array}{c}\text { Number of } \\
\text { patients }\end{array}$ & $\begin{array}{c}\text { Previous } \\
\text { antibiotics }\end{array}$ & $\begin{array}{c}\% \text { of } \\
\text { patients }\end{array}$ & $P^{*}$ \\
\hline $\begin{array}{l}\text { Chronic care ward } \\
\quad \text { Colonization + }\end{array}$ & 10 & 3 & 30 & NS \\
$\quad$ Colonization - & 39 & 11 & 28 & \\
$\begin{array}{l}\text { Acute care ward (prevalence study) } \\
\quad \text { Colonization + }\end{array}$ & 4 & 4 & 100 & NS \\
$\quad$ Colonization - & 25 & 19 & 76 & \\
$\begin{array}{l}\text { Acute care ward (prospective study) } \\
\quad \text { Colonization + } \\
\quad \text { Colonization - }\end{array}$ & 14 & 12 & 86 & NS \\
\hline
\end{tabular}

*Fisher exact test; NS = not significant. 
The acquisition rate we found in the acute geriatric ward is very similar to the $13.7 \%$ prevalence rate we had determined in this same ward at the beginning of our study. McFarland et al. ${ }^{11}$ found $20 \%$ positive cultures from staff members and up to $49 \%$ positive environmental cultures. Kaatz et al..$^{13}$ recovered $C$. difficile from $31.4 \%$ of environmental cultures. The aforementioned environmental studies were carried out in context of rather high level disease rate ${ }^{11}$ or under actual epidemic conditions. ${ }^{13}$ While $C$. difficile is undoubtedly transmitted from patient by personnel or environmental sources, our difficulty in detecting this contamination except on fomites which are directly contaminated by faeces further underscores the probable low bacterial load in our totally asymptomatic population.

\section{References}

1. Bartlett, J.G., Chang, T.W., Gurwith, M., Gorbach, S.L. \& Onderdonk, A.B. Antibiotic-associated pseudomembranous colitis due to toxin-producing clostridia. N Engl J Med 1978, 298: 531-534.

2. Bennett, G.C.J., Allen, E. \& Millard, P.H. Clostridium difficile diarrhoea: a highly infectious organism. Age Ageing 1984, 13: 363-366.

3. Bender, B.S., Bennett, R.G., Laughon, G.E. et al. Is Clostridium difficile endemic in chronic-care facilities? Lancet 1986 , 2: $11-13$.

4. Bennett, R.G., Laughon, B.E., Mundy, L.M. et al. Evaluation of latex test for Clostridium difficile in two nursing home outbreaks. J Clin Microbiol 1989, 27: 889-893.

5. Campbell, R.R., Beere, B., Wilcock, G.K. \& Brown, E.M. Clostridium difficile in acute and longstay elderly patients. Age Ageing 1988, 17: 333-336.

6. Corrado, O.J., Mascie-Taylor, B.H., Hall, M.J. \& Bolton, R.P. Prevalence of Clostridium difficile on a mixed function ward for the elderly. J Infect 1990, 21: 287-292.

7. McFarland, L.V., Coyle, M.B., Kremer, W.H. \& Stamm, W.E. Rectal swab cultures for Clostridium difficile surveillance studies. J Clin Microbiol 1987, 25: 2241-2242.
In summary, we have found significant $C$. difficile colonization amongst both acute and chronic care geriatric patients, even under non-epidemic conditions.

This organism seems to be principally nosocomially acquired causing mainly asymptomatic infection. At times, for some as yet unknown reasons, this reservoir can become the source of symptomatic and even life-threatening outbreaks of disease.

\section{Acknowledgements}

Our thanks to Ms D. Attias and Ms E. Stern for their technical and secretarial assistance.

8. Bate, G. Comparison of Minitek Anaerobe II, API An-Ident and RapID ANA systems for identification of Clostridium difficile. Am J Clin Pathol 1986, 85: 716-718.

9. Borriello, S.P. \& Barclay, F.E. Clostridium difficile in the elderly. J Infect 1991, 22: 310-312.

10. Thomas, D.R., Bennett, R.G., Laughon, B.E. et al. Postantibiotic colonization with Clostridium difficile in nursing home patients. J Am Genatric Soc 1990, 38: 415-420.

11. McFarland, L.V., Mulligan, M.E., Kwok, R.Y.Y. et al. Nosocomial acquisition of Clostridium difficile infection. $N$ Engl J Med 1989, 320: 204-210.

12. Johnson, S., Clabots, C.R., Linn, F.V. et al. Nosocomial Clostridium difficile colonisation and disease. Lancet 1990 336: $97-100$.

13. Kaatz, G.W., Gitlin, S.D., Schaberg, D.R. et al. Acquisition of Clostridium difficile from the hospital environment. Am J Epidemiol 1988, 127: 1289-1294. 